\title{
Intellectual capital research and practice: 7 myths and one golden rule
}

\author{
Constantin BRATIANU \\ The Bucharest University of Economic Studies, Bucharest, Romania \\ Academy of Romanian Scientist, Bucharest, Romania \\ constantin.bratianu@gmail.com
}

\begin{abstract}
The intellectual capital research and practice entered in the last years into a visible decline due to some barriers in understanding its intangible nature and designing Newtonian metrics for its measurement and reporting. Inertial thinking is very powerful in promoting new approaches for the need of a new perspective in working with intellectual capital. Unfortunately, even some top journals in the domain of intellectual capital remained trapped into this Newtonian logic and standard statistical analysis, as a result of the mind-set of their editorial staff and reviewers. The purpose of this paper is to present a critical analysis of the intellectual capital research and practice today and to reveal some of the most important barriers in understanding the complexity and nature of the intellectual capital. These barriers manifest like myths in approaching the research into intellectual capital, myths that create a false reality and false research questions, which enter into collision with the real life of companies and their business. The paper identifies seven myths which created a Newtonian version of the nonNewtonian reality, and a golden rule for further research into the intellectual capital of organizations. The conclusion of the present critical analysis is that we need a new approach to understand the complexity of the intellectual capital and new metrics to measure it.
\end{abstract}

Keywords: intellectual capital, knowledge, metaphorical thinking, rationality, emotionality, spirituality, linearity.

Please cite the article as follows: Bratianu, C. (2018), "Intellectual capital research and practice: 7 myths and one golden rule", Management \& Marketing. Challenges for the Knowledge Society, Vol. 13, No. 2, pp. 859-879, DOI: 10.2478/mmcks-2018-0010.

\section{Introduction}

The concept of intellectual capital appeared when people could not explain the value paradox of some new type of companies, called knowledge companies, for which their stock value is three, five, or ten times the book value of their assets. The answer came when experts discovered that the intangible resources of those companies became dominant with respect to the traditional hard or tangible resources. As Stewart (1999, p. 55) remarks, "The hard assets of a knowledge company contribute far less to the value of its ultimate product (or service) than the intangible assets - the talents of its people, the efficacy of its management systems, the character of its relationships to its customers - that together are the intellectual capital". Intellectual capital is the hidden value of a knowledge company and it is very hard to reveal it and to measure it. As a logical consequence of that, it is very difficult to define it. For the purpose of our research, we choose the definition formulated by Roos, Pike and Fernström (2005, p. 19): "Intellectual capital (IC) can be defined as all nonmonetary and nonphysical resources that are fully or partly controlled by the organization and that contribute to the organization's value creation". Since monetary and physical resources are 
tangible, it results that the definition refers to the intangible resources. That is emphasized also by Stewart (1999, p. XI): "Intellectual capital is intellectual material knowledge, information, intellectual property, experience - that can be put to use to create wealth".

Although the definition of the intellectual capital looks well-formulated, its interpretation remains difficult due to the fuzzy nature of its semantic field which is composed of two different semantic fields associated to the concepts of capital and intellectual (see Figure 1). Also, interpretation and understanding the deep meaning of this integrated concept depends on our metaphorical thinking (Andriessen, 2004, 2006, 2008; Andriessen and Boom, 2007; Boroditsky, 2000; Gentner et al., 2001; Lakoff and Johnson, 1980, 1999).

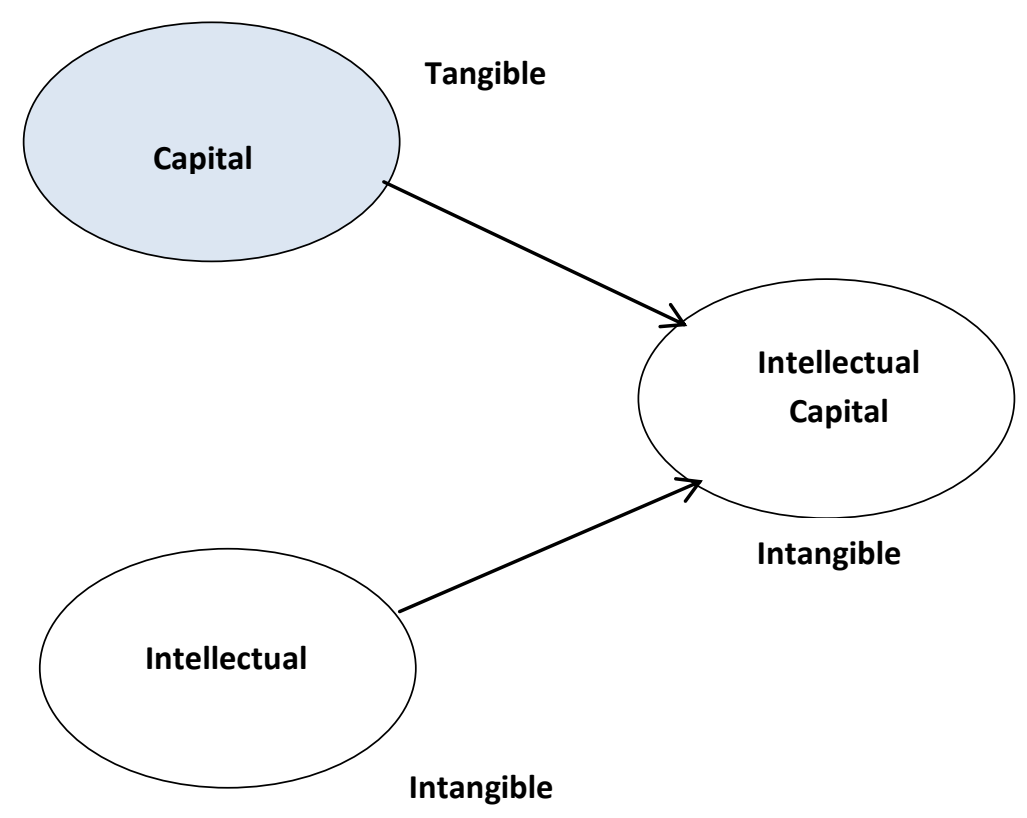

Figure 1. The composition of the semantic field

Source: Author's research.

Metaphors play a vital role in developing our knowledge field by initiating new perspectives of meaning associations and of using them in the decision making process. Andriessen (2004; 2006; 2008), and Andriessen and Boom (2007) have shown that knowledge management and intellectual capital theories developed in these last decades have been based primarily on using metaphors. "Knowledge is an abstract concept. It has no referent in the real world. We use metaphor to map elements of things we are familiar with in the real world (organisms, resources, products) onto the concept of knowledge to make it comprehensible. Knowledge is not a concept that has a clearly delineated structure. Whatever structure it has it gets through metaphor" (Andriessen, 2006, p.96).

The same statement can be made about the concept of intellectual capital. According to Andriessen (2006), the concept of intellectual capital is a result of three metaphors focused on the following ideas: knowledge as a resource, knowledge as 
capital, and being intellectual. The "knowledge as a resource" metaphor reveals one of the most popular strategic views of a company: the resource-based viewed (RBV). According to this view, a company is considered as a bundle of resources and capabilities which contribute decisively to the competitive advantage. According to Barney and Hesterly (2012, p. 84), "The RBV is a model of firm performance that focuses on the resources and capabilities controlled by a firm as sources of competitive advantage". Capabilities are those capacities of a firm which enable it to process efficiently its resources to create value for society. The "knowledge as capital" metaphor is developed from the previous metaphor with some new attributes mapped onto the concept of intellectual capital. These attributes reflect the meaning of the capital which is basically a resource, but with the property of generating interest in the economic process of the firm. Thus, this metaphor induces the ideas that "capital is valuable and important", "having more capital is better", "capital can be valued financially", and "capital allows for a return" (Andriessen, 2006; Marr, 2005). The third metaphor based on the attribute of "being intellectual" introduces the idea of intangibility, which is essential for understanding the nature of the new concept.

The purpose of this paper is to critically analyse the way in which the concept of "intellectual capital" has been understood and used in practice by both researchers and practitioners. Having in mind the difficulties created by the conflicting semantics illustrated in figure 1 and by the different interpretations resulted from the metaphorical approach, we shall identify seven myths concerning the concept of intellectual capital and how they shaped its understanding and implementation in operational management. Unfortunately, all of these myths constitute limitations of our understanding and due to these limitations many results obtained in implementing the concept of intellectual capital have been flawed. Researchers and practitioners should overcome these limitations by creating a better understanding of the intellectual capital and its semantic attributes.

\section{Methodology}

This is a conceptual paper based on a critical analysis of literature dedicated to intellectual capital, coming from both researchers and practitioners and on reconsidering the metaphorical approach used in explaining the semantic attributes of the new concept. It is a qualitative research into the realm of intellectual capital based mostly on analysing the semantic fields used for defining and explaining the concept of intellectual capital, as well as contrasting them with the practical results of using this concept in measuring and reporting the intellectual capital of organizations. Metaphorical thinking is fundamental in performing our research since it gives the overall framework of our analysis. As Pinker (2008, p. 241) explains, "Conceptual metaphors point to an obvious way in which people could learned to reason about new, abstract concepts. They would notice or have pointed out to them, a parallel between a physical realm they already understand and conceptual realm they don't yet understand". Metaphorical thinking means to analyse the attributes and relationships from the source domain and to compare them with the situation from the target domain trying to identify which of these elements can be transferred from the source domain into the target domain. Theoretically, we perform a structural 
mapping of the known attributes and relationships from the source domain onto the target domain (see Figure2).

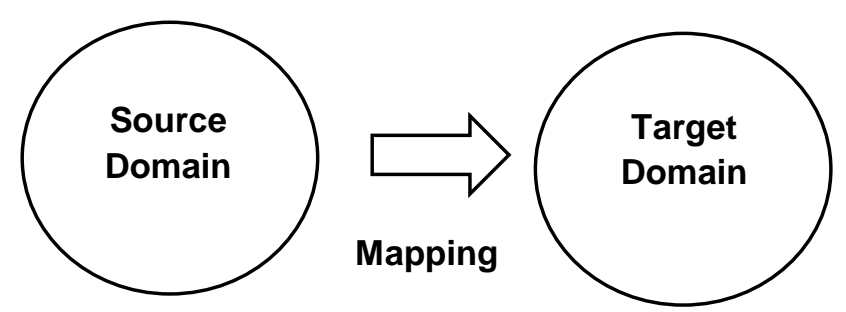

Figure 2. The structure of a conceptual metaphor

Source: Adaptation after Andriessen (2006).

Since knowledge is the dominant component of intellectual capital, metaphors used for knowledge have been used also for understanding intellectual capital (Andriessen, 2006, 2008). We shall make use of some of these knowledge metaphors in discussing the seven myths and their consequences on shaping our understanding of both concepts.

\section{Myth \#1: Intellectual capital is linear}

One of the most frequently used definition of the intellectual capital is that formulated by Stewart (1999, p. XI): "Intellectual capital is the sum of everything everybody in a company knows that gives it a competitive advantage [...] Intellectual capital is intellectual material, knowledge, experience, intellectual property, information [...] that can be put to use to create wealth" (our emphasis). Dumay (2016, p. 169) reformulates this definition changing the concept of "wealth" with that of "value", but keeping the idea that intellectual capital is "the sum of everything everybody in a company knows that gives it a competitive advantage". The key concept of this definition is the concept of sum which emphasizes the property of linearity for the intellectual capital.

In Mathematics, the concept of sum and the operation of summation or addition belong to the complex concept of linear space. By definition, "A vector (linear) space is where all linear combinations of elements are also elements of the space. This is easy for spaces of numbers but not for a space of functions. Roughly, this is to say that multiplication by numbers, and addition of elements is defined in the space" (The Free Online Dictionary of Computing). Thus, a vector (linear) space is a set $\mathrm{V}$ together with two operations, + and $\mathrm{x}$. The following are the mathematical requirements for a space to be a linear space, containing for simplicity a field of scalars representing numbers (Bratianu, 2009, p. 416):

- If $a$ and $b$ are scalars in $S$, then $a+b$ is also a scalar in $S$.

- If $c$ is a scalar in $S$, then $c a$ is also a scalar in $S$.

- The scalar addition is commutative: $a+b=b+a$.

- The scalar addition is associative: $(a+b)+c=a+(b+c)$.

- There is an identity element such that: $a+0=0+a$.

Vol. 13, No. 2, Summer, pp. 859-879, ISSN 1842-0206 | Management \& Marketing. Challenges for the Knowledge Society 
- There is an inverse element such that: $a+(-a)=0$.

- There is distributivity over scalar addition: $(a+b) c=a c+b c$.

The economic Capital is a measurable concept, and it can be expressed in numbers. The easy way to evaluate the source domain is to consider the money metric, which means to play with simple numbers. Let us consider three arbitrary numbers representing money: $\mathrm{a}=3 ; \mathrm{b}=5 ; \mathrm{c}=10$. Let $N$ be the set of all natural numbers. Then, let us apply the scalar requirements:

- If 3 and 5 are numbers in $\mathrm{N}$, then $3+5$ is also a number in $\mathrm{N}$.

- If 10 is a number in $\mathrm{N}$, then $10 \times 3$ is also a number in $\mathrm{N}$.

- The number addition is commutative: $3+5=5+3$.

- The number addition is associative: $(3+5)+10=3+(5+10)$.

- There is an identity element such that: $3+0=0+3$.

- There is an inverse element such that: $3+(-3)=0$.

- There is distributivity over number addition: $(3+5) \times 10=3 \times 10+5 \times 10$.

As it can be seen the semantic field of the economic capital concept placed in the source domain of the metaphor "intellectual capital is capital" (Figure 3) is linear since all properties of the scalar linear space are satisfied. Unfortunately, this property has been mapped onto the target domain of the intellectual capital, and many researchers and practitioners make use of it in measuring the value of the intellectual capital in a given organization (Federal Law Gazette, 2006; Habersam et al., 2013, 2018; Ricceri, 2008).

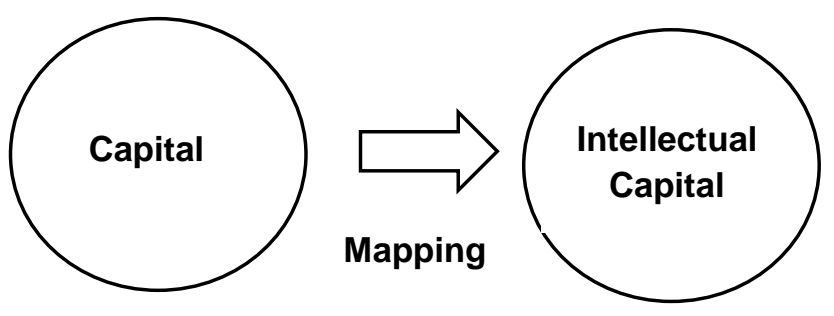

Figure 3. The structure of the intellectual capital metaphor

Source: The author' research.

Linearity is a generic approach for people to reduce complexity of any problem by approximating it with a simpler, linear problem for which a solution can be found in a faster and easier way. The key correlation in a linear problem is the proportionality between the output and input variables. For instance, measuring physical objects attributes like mass, volume, or temperature can be done by using measuring systems based on linear properties of those attributes. Also, time is linearized when measured by a clock since the biological time is nonlinear. Many people receive linear salary, since the monthly payment is proportional with the total number of working hours. It is a paradox the fact that a university professor in a state university in Europe is paid for what he is not doing! The linearity of his salary is far Vol. 13, No. 2, Summer, pp. 859-879, ISSN 1842-0206 | Management \& Marketing. Challenges for the Knowledge Society 
away from the nonlinearity of the teaching process. In such a cultural mindset, there is no wonder that many researchers considered almost naturally to use linearity in defining and measuring intellectual capital.

Intellectual capital and knowledge are two semantic entities for which the rules of linear spaces cannot be applied. Let us consider a semantic field S containing all the words in a given natural language, and two words taken randomly, like computer and cheese. By applying the first rule, the addition rule, it results: computer + cheese = computercheese. However, such a word does not exist and thus, the semantic space is not linear. Looking further into the linear space properties one remarks the absence of a "zero" element in the semantic field, since each element belonging to such a field has got a certain significance. Also, it would be difficult to prove the existence of an "inverse" element which will cancel the "normal" one. For instance, if one considers the normal element the expression "John is tall", then the inverse element will be "John is not tall", and their addition to yield zero: (John is tall) + (John is not tall) $=0$. However, such a statement cannot exist. Instead of "zero" the final result is ambiguity. All of these examples come to demonstrate that knowledge expressed into a natural language cannot be treated as a linear space and the idea of knowledge summation is flawed. The same can be said for the intellectual capital, which cannot be considered a sum of everything everyone knows in a company. Knowledge and intellectual capital are nonlinear entities, and for such entities one must use the idea of integration instead of summation.

\section{Myth \#2: Intellectual capital is static}

When researchers use the first generation metaphors for knowledge based on objects or stocks, the resulting idea for the intellectual capital is that of a stock. The stock idea is related also with the resource-based view of the company, where the focus is on the strategic dimension of deploying resources (Andriessen, 2004; Barney, 1991; Hadad, 2017; Mouritsen and Larsen, 2005; Ricceri, 2008; Spender, 2015; Wernerfelt, 1984). Since a stock is a static entity, it results that the intellectual capital is static. "The static asset approach adheres to the cognitivist perspective on knowledge, which assumes knowledge can be managed with tight procedures, policies and defined action. It is also closer to the resource-based view of the firm, where the main interest is in acquisition and protection of valuable, rare, inimitable and nonsubstitutable resources" (Kianto, 2007, p. 346). The static view of intellectual capital has been adopted mostly by those involved in accounting research and practice (Bontis, 1999).

The new wave of knowledge metaphors focus on the fluids, flows, and stocksand-flows entities as source semantic domains. Knowledge and intellectual capital become dynamic entities. Using a mechanical analogy, Nissen (2006, p. XX) conceives knowledge as a fluid flowing through the whole organization: "To the extent that organizational knowledge does not exists in the form needed for application or at the place and time required to enable work performance, then it must flow from how it exists and where it is located to how and where it is needed. This is the concept knowledge flows". Moreover, knowledge flow is related directly to the managerial performance: "Rapid and reliable flows of knowledge across people, organizations, times, and places are critical to enterprise performance" (Nissen, 2006, p. IX). The knowledge metaphor stocks-and flows integrates both static and dynamic properties. 
The concept of stock suggests the level of knowledge which exists at a given moment in a specific place in organization. The concept of flow suggests the transfer of knowledge from one person to another, in a social context. According to this interpretation, the metaphor reflects much better the organizational knowledge dynamics (Bolisani and Oltramari, 2012).

It is interesting to note that in the static approach knowledge is understood mostly in its explicit form, while in the dynamic approach knowledge appear in both explicit and tacit modes. Kianto (2007, p. 344) explains that in the dynamic interpretation "knowledge is understood as emerging from the ongoing interactions between the organizational members, and the focus is not on the intangible assets per $s e$ but on the organizational capabilities to leverage, develop and change intangible assets for value creation". Organizational capabilities are managerial capacities for processing information and knowledge resources and incorporating them into the products and services delivered on the market (Grant, 1996; Teece et al., 1997). Kianto (2007) identifies three different interpretations for intellectual capital dynamics:

- Dynamics resulted from intangibles interactions in the process of value creation.

- Dynamics resulted from the dynamics of organizational activities and processes.

- Dynamics resulted from the organizational change processes.

For Kianto (2007), intellectual capital dynamics results from a deductive logic: if there are interactions and processes which lead to variations and motions in time and space within the organization, which means that the intellectual capital involved in them display a dynamic behaviour. In a recent research, Kianto et al. (2017) raised the question of intellectual capital behaviour during a longer period of time for a company, introducing the idea of the temporality. That means to evaluate the intellectual capital of a company at different moments in time (i.e. years) and analyse its variation.

A new perspective on the intellectual capital dynamics in organizations presents Bratianu (2011) based on the knowledge as energy metaphor (Bratianu and Andriessen, 2008). This perspective is further developed in creating the entropic intellectual capital model (Bratianu and Orzea, 2013a), and knowledge strategies (Bolisani and Bratianu, 2017; Bratianu and Bolisani, 2015). The basic idea of this new perspective is to overcome the limitations of the Nonaka's knowledge dynamics model (Bratianu, 2010) by introducing a new paradigm for knowledge understanding based on thermodynamics. The organizational knowledge is conceived as a multifield composed of rational knowledge, emotional knowledge and spiritual knowledge. Each form of knowledge can be transformed into another form of knowledge which creates an entropic knowledge dynamics (Bratianu and Orzea, 2013a, 2013b). Thus, the mechanical model used in explaining knowledge dynamics is substituted with the thermodynamic model which is much more advanced. Knowledge dynamics means much more than knowledge flows through organization; it means knowledge transformation in time and space from one form into another one: rational knowledge into emotional knowledge and vice versa, emotional knowledge into spiritual knowledge and vice versa, and spiritual knowledge into rational knowledge and vice 
versa. From this point of view we agree with Kianto et al. (2017, p. 135) who posit that "Knowledge, in essence, is fundamentally dynamic. A socially constructed issue, knowledge is crafted and disseminated through interpersonal interactions and negotiations, where it is continuously re-interpreted and modified, and thus related to learning and change".

\section{Myth \#3 Intellectual capital is rational}

Since knowledge is the basic ingredient of the intellectual capital, we should start with it and recognize that most of the researchers are interested in explicit knowledge, which is rational. Rational knowledge has got a long tradition coming from the ancient Greek. Plato (Russell, 1972) was one of the first philosophers to consider knowledge as being rational, and then Descartes (1997, p. 147) developed this idea concluding that "Even bodies are not properly speaking known by the senses or by the faculty of imagination, but by the understanding only, and since they are not known from the fact that they are seen or touched, but only because they are understood, I see clearly that there is nothing which is easier for me to know than my mind". Thus, "knowledge consists in reflection, not in impressions, and perception is not knowledge" (Russell, 1972, p, 153).

However, tacit knowledge shows the importance of emotions, insights, intuitions, hunches and values (Nonaka and Takeuchi, 1995) which are not rational. They are non-rational, having emotional and spiritual roots (Damasio, 1999, 2012; Ekman, 2003; Gardner, 1983; Gladwell, 2005; Zohar and Marshall, 2000, 2004). Emotional knowledge is the hidden part of the iceberg, but its role in organizational knowledge becomes more and more important (Bratianu and Orzea, 2013b). Emotional knowledge is wordless knowledge reflecting emotions and feelings, and having an important contribution in the decision-making process: "Breakthroughs in brain science have revealed that people are primarily emotional decision makers" (Hill, 2008, p. 2). Moreover, the entropic knowledge dynamics is a driving force of the managerial decision-making (Bejinaru, 2017; Bratianu and Vatamanescu, 2018). In any organization, emotional knowledge is used for motivating employees and constitutes a basic component of the organizational culture (Ghinea and Bratianu, 2012; Schein, 2004).

Spiritual knowledge integrates values and beliefs about life, work, and our existence. All of these determine the essence of the spiritual capital (Zohar and Marshall, 2004, p. 27): "Our spiritual capital is our shared meaning, our shared purpose, our shared vision of what most deeply matters in life - and how these are implemented in our lives and in our behavioural strategies. It is the capital that is increased by drawing on the resources of the human spirit". Spiritual capital is about shared values, but in any organization there are positive and negative cultural values. While positive values contribute to performance and well-being for company and society, negative values lead to an exaggerated focus on profit maximization and destruction of the environment. Corporate social responsibility (CSR) has been developed in the last decades as a driving force oriented to limit the greedy attitude of some shareholders and managers who base their decisions only on the principle of profit maximization (Basu and Palazzo, 2008; Devinney, 2009; Porter and Kramer, 2011). Spiritual knowledge and spiritual intelligence could have a direct influence on 
changing the business process focused on negative values. "The focus on profit being king has caused significant negative, unintended consequences. For over a century and a half cheap labour, damaged lives, a destroyed planet and polluted seas were all irrelevant when set against the need for profit. But this is changing" (Branson, 2011, p.21).

Starting with the three fundamental fields of organizational knowledge rational, emotional, and spiritual - we may consider three basic entities of intellectual capital: rational capital, emotional capital, and spiritual capital. Thus, human capital, structural capital and relational capital appear as meta-constructs in the whole organizational framework and not as basic components of the intellectual capital. That will change the canonical model of the intellectual capita, as will be shown in the next section of this paper.

\section{Myth \#4 The building blocks of the intellectual capital are: human capital, structural capital, and relational capital}

After some variations on the basic structure of the intellectual capital initiated by Stewart (1997), Sveiby (1997), Edvinsson and Malone (1997), most researchers agreed upon the canonical model of the intellectual capital illustrated in Figure 4 (Andriessen, 2004; MERITUM, 2002; Ricceri, 2008).

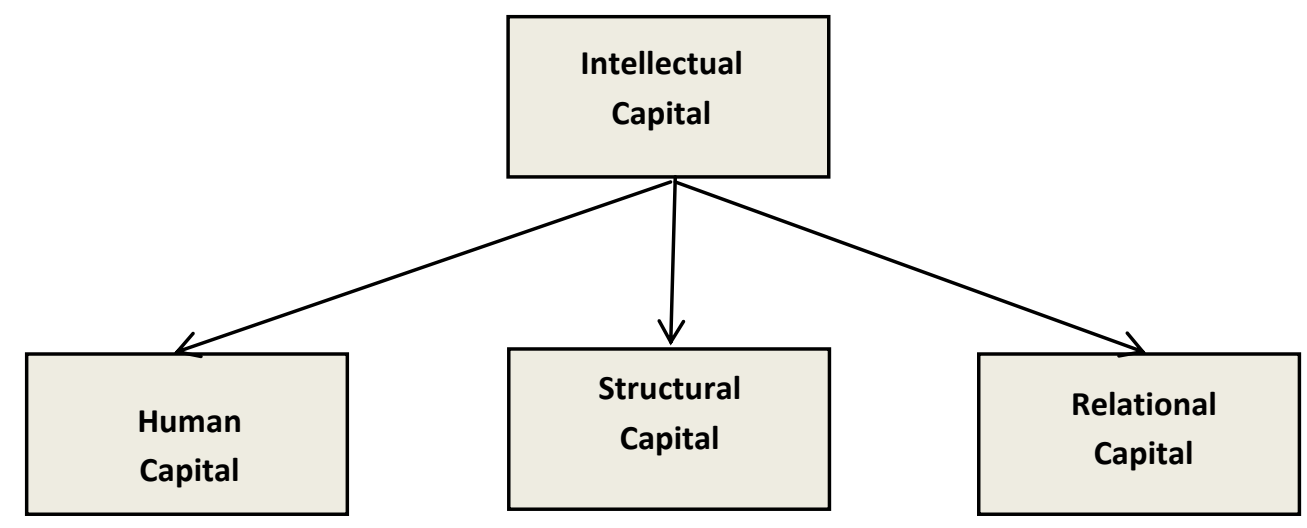

Figure 4. The canonical model of the intellectual capital

Source: Andriessen (2004)

Human capital contains all the knowledge employees have, including their experience, skills, and abilities. Examples are their explicit and tacit knowledge, innovation capacity, creativity, teamwork spirit, motivation, learning capacity, flexibility and tolerance. Many researchers consider human capital as being the most important component of the intellectual capital since knowledge is generated at the individual level, by people interactions with other people and with the environment.

Structural capital is defined as knowledge that remains in the firm after all employees live for home, by the end of the working day. It contains organizational knowledge which is embedded in the organization's governance, regulations, 
procedures, documentation, databases, patents, and organizational culture. Some authors call this component organizational capital, in order to underline the importance of organizational knowledge in its definition. In practice, structural capital may create some restrictions or limitations in leveraging efficiently the human and relational capital.

Relational capital is defined as all resources linked to the external relationships of the firms, including suppliers, customers, investors, and any business partners. Relational capital is focused mostly on customers and the business environment, containing the image of the firm, customers' loyalty, customers' satisfaction, and all information obtained through business intelligence.

The canonical model presented in Figure 4 is great as much as we would like to see the big picture of the intellectual capital at the organizational level. However, the three entities in this model - human capital, structural capital, and relational capital are not independent entities and they are not the fundamental components of the organizational intellectual capital. As a logical consequence, any evaluation will yield wrong results since there are many indicators which may be considered associated to any of these entities, or indicators which reflect the overlapping zones between these three entities. The conclusion is that this canonical model is a meta-construct and we should find a deeper level of decomposition, with some independent entities.

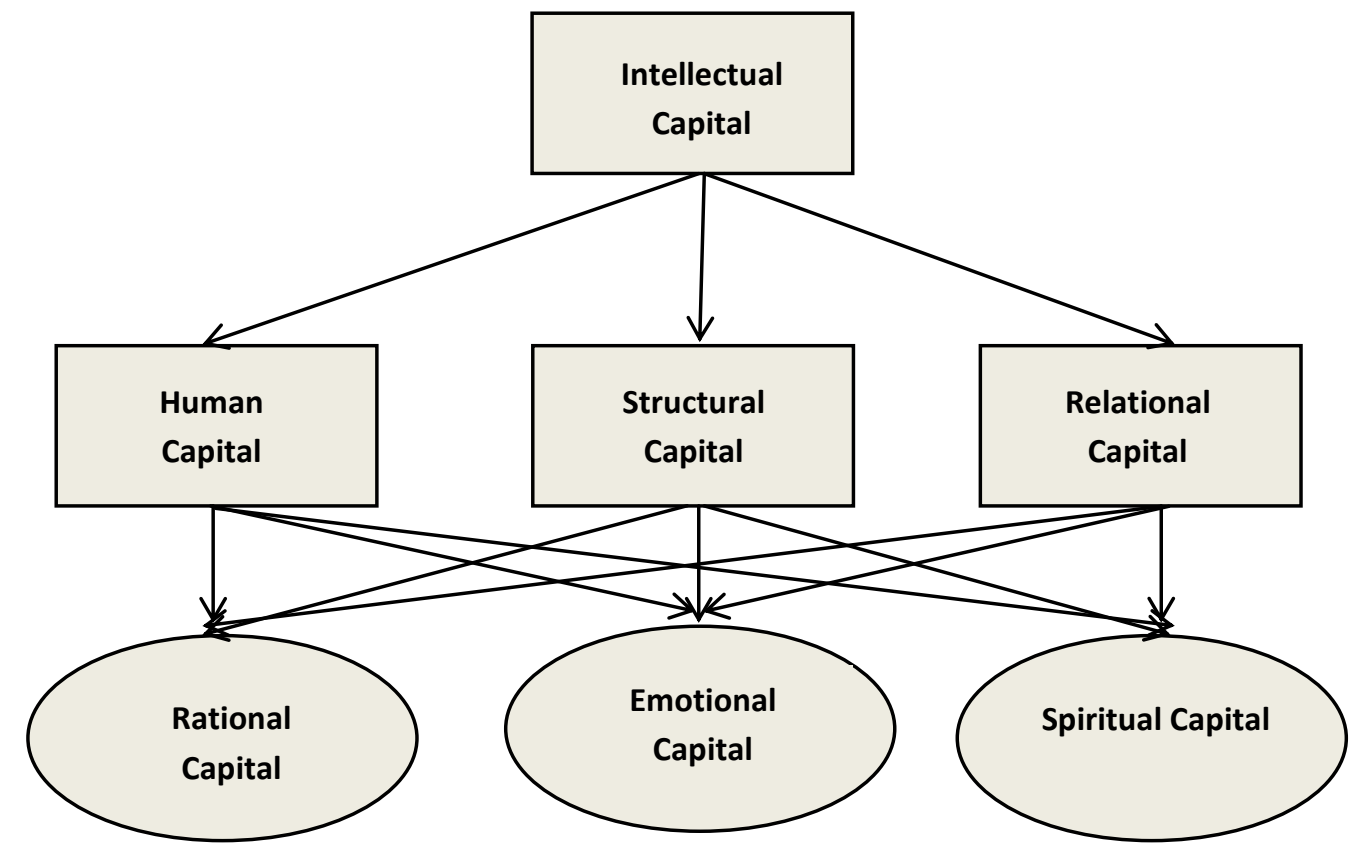

Figure 5. The new model for the intellectual capital

Source: Adaptation after Bratianu and Bejinaru (2017)

Rational knowledge, emotional knowledge and spiritual knowledge can be found in each entity of the canonical model of the intellectual capital, which leads to the idea of decomposing them in these basic ingredients and then re-structuring them into three new fundamental components of the organizational intellectual capital: 
rational capital, emotional capital and spiritual capital. The model of this new intellectual capital view is illustrated in Figure 5.

The new basic building blocks of the intellectual capital are independent entities and logically there are no overlapping zones between them. The new model of the organizational intellectual capital can be evaluated by measuring rational capital, emotional capital and spiritual capital by using specific metrics which can be developed similarly with the metrics used for measuring rational intelligence (IQ), emotional intelligence (EQ), and spiritual intelligence (SQ). These metrics should consider the fact that intellectual capital is not tangible, is not linear, and is not static, as shown above.

\section{Myth \#5 The critical component of the intellectual capital is human capital}

Knowledge is created in the minds of people as a result of their actions and interactions, and only through a process of integrating all the employees' knowledge it is possible to obtain the intellectual capital of a given organization (Bontis, 1999; Nonaka and Takeuchi, 1995; Stewart, 1997). Since structural capital and relational capital are built on the same knowledge, it is almost natural to consider that human capital constitutes the critical component of the intellectual capital, which means that it is the capital related directly to the power of decision makers. However, in practice we see many organizations which have excellent human resources but no performance. It is a paradox, but it is real. Moreover, intelligent human capital may lead to a functional stupidity: "Intelligent people, when assembled into an organization, will tend toward collective stupidity" (Albrecht, 2003, p. 4). Reflecting on his own experience as a business consultant, Albrecht (2003, p. 3) remarks: "As an organizational consultant, I've seen a remarkable array of failure patterns in a wide variety of enterprises. I've seen many more businesses defeated by their own internal maladjustments than beaten fair and square by worthy competitors". In the same direction point Alvesson and Spicer (2016, p. XI) who ask: "Why was it that organizations which employed so many smart people could foster so much stupidity?". There is only one possible answer: due to the structural capital.

Structural capital embodies the managerial philosophy of the organization, philosophy which contributes to the formation of the organizational culture and to all written regulations and procedures. That means from the practical point of view that structural capital represents the organizational framework of the decision-making. Even if the human capital contains intelligent people, stupid regulations will lead managers to stupid decisions and finally to business failure. According to Alvesson and Spicer (2016, p. 71), "Most stupidity in corporate life takes the form of functional stupidity. This involves narrow thinking rather than pure thoughtlessness, which is normal (in the sense of commonplace), and has functional consequences - at least in the short term". 


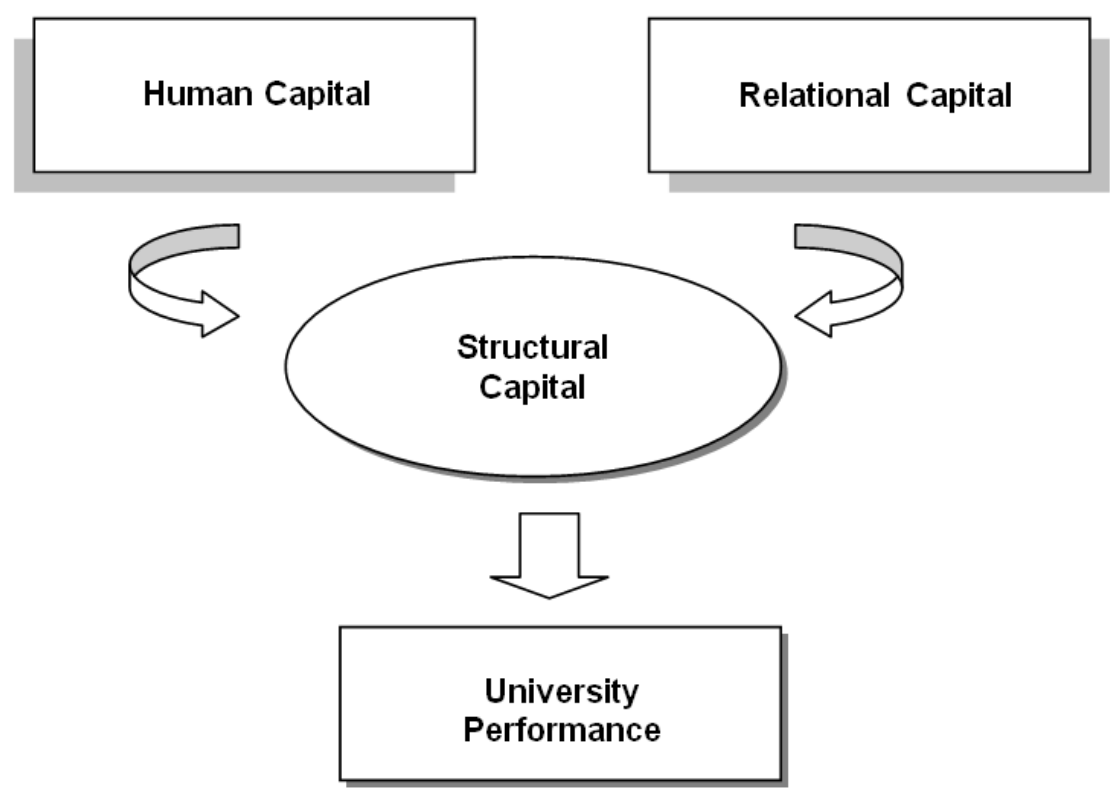

Figure 6. The Gordian Knot of the university intellectual capital

Source: Bratianu and Orzea (2013c)

Human capital is the only intellectual capital which is capable of knowledge creation, and from this point of view is essential. However, the potential of the human capital can be used only in the framework of structural capital, which transforms this structural capital in a critical component of the organizational intellectual capital. In other words, structural capital controls how much of the human capital potential is transformed into operational capital and embedded into products and services. This situation is typical not only for firms but also for universities (Bratianu and Orzea, 2013c; Dima and Ghinea, 2016). The performance of a university depends ultimately on the capacity of the structural capital to use intelligently and creatively the human capital (see Figure 6).

\section{Myth \#6 The performance of the firm depends on the intellectual capital potential}

Most authors consider that intellectual capital is a potential for value creation and that firm's performance is directly related to this potential (Goran, et al., 2005; Goran and Jutur, 2005; Mauritsen and Larsen, 2005; Ricceri, 2008; Spender, 2015; Stewart, 1997). It is the approach of those researchers who design their investigations based on the resource based view of the firm (Barney and Hesterly, 2012). However, the conception of the intellectual capital as a potential is a static view which is in contradiction with the real organizational processes and their performance. Bratianu (2013) demonstrated based on the metaphorical thinking and thermodynamics principles that the intellectual capital suffers a continuous transformation, within a generic organization, from a potential state to an operational state, similarly to the transformation of potential energy into kinetic energy. This process is illustrated in Figure 7.

Vol. 13, No. 2, Summer, pp. 859-879, ISSN 1842-0206 | Management \& Marketing. Challenges for the Knowledge Society 


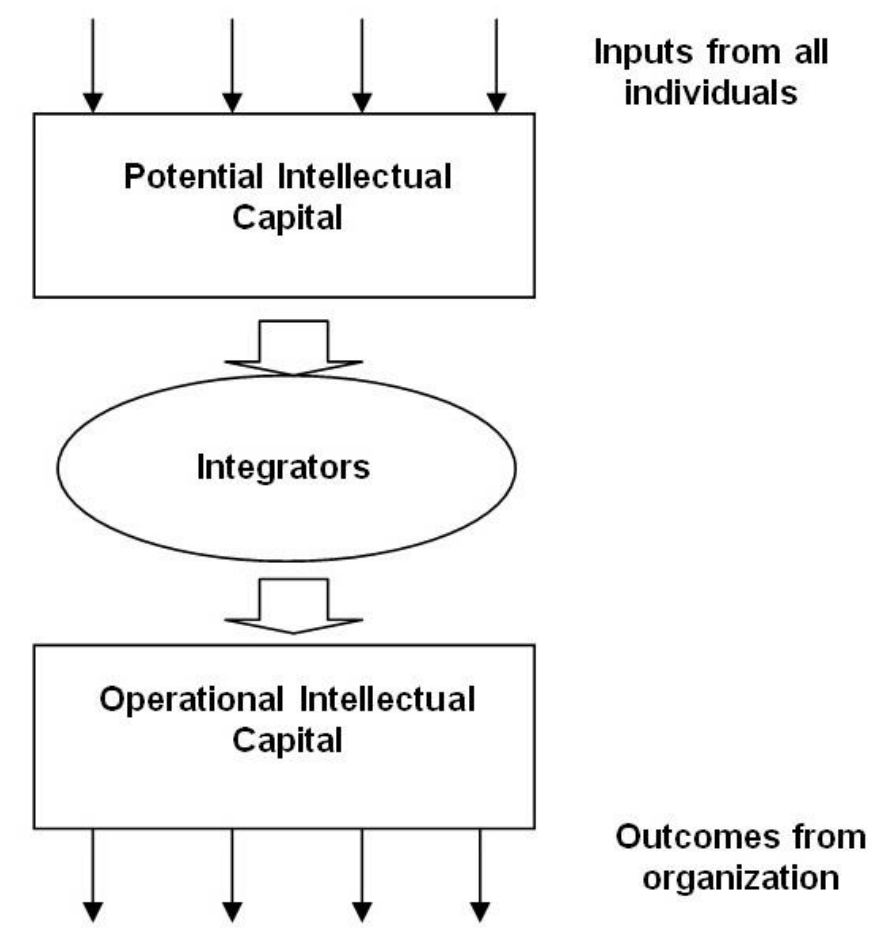

Figure 7. The dynamics of intellectual capital

Source: Bratianu and Orzea (2013c)

The transformation process is done by nonlinear integrators (Bratianu, 2013). The organizational nonlinear integrators are: technology and processes, management, leadership, and organizational culture. As it can be seen, these integrators operate within the structural capital framework and they can enable or constrain the transformation of the potential intellectual capital into the operational intellectual capital (Agoston and Dima, 2012; Bolisani and Bratianu, 2017). Finally, only the operational intellectual capital can be used for value creation, which implies that only the operational intellectual capital can be related to the firm's performance. The transformation is done in time and in a very well-defined organizational context. Theoretically, two firms with comparable intellectual capital potential may have different levels of operational intellectual capital and different performances.

Giuliani (2015) emphasizes the importance of time, of creation and destruction in evaluating the intellectual capital. Also, he recognizes the importance of considering the two different views on the intellectual capital: "Among the several perspectives from which IC can be observed, two main approaches, one static and one dynamic, can be identified. While the former focuses on the stock of IC resources, investigating how they can be visualized and quantified by subscribing to the old adage 'you can manage what you can measure', the latter is instead centred on flows, processes, rules, activities, and connections, i.e. on the value creation process" (Giulinai, 2015, p. 4). Thus, the dynamic view leads to the operational intellectual capital, or to the 
intellectual capital-in-action as conceived by Cuganesan (2005), Cuganesan and Dumay (2009).

\section{Myth \#7 Intellectual capital can be reported within the accounting framework}

Pioneers of the intellectual capital (Edvinsson and Malone, 1997; Stewart, 1997; Sveiby, 1997) considered that evaluating and reporting intellectual capital will lead to a better profitability for the firm. The grand theory (Dumay, 2012) behind this idea has been explained by Bismuth and Tojo (2008, p. 242): "Providing the market with sufficient and appropriate information about intellectual assets improves decisionmaking by investors and helps discipline management and boards with positive economic consequences. Ensuring that the non-financial information is consistent, comparable over time and across companies, material and reliable would allow investors to better assess future earnings and the risks associated with different investment opportunities, thus reducing information asymmetry, reducing biased or unfounded earnings estimates, unrealistic valuations and unjustified share price volatility". Despite this logic, the practice showed that many of the first firms performing measurements of intellectual capital and producing reports on it, abandoned that activity very soon. A good example is Skandia which was the first firm to elaborate such an intellectual capital report and renounced at it in 1998 (Dumay, 2012).

The real problem with measuring IC is its complexity and nonlinear behaviour. Any attempt to measure it by using linear metrics produced questionable results and interpretations. Using the old managerial methods with 'accounting' metrics for the new and complex phenomena leads to the misuse of the IC measurement frameworks. As Dumay (2009, p. 205) remarks, "these contemporary IC measurement frameworks are reifying IC in the same manner in which tangible assets are portrayed within accounting, which is akin to attempting to make the intangible tangible. This is what the author defines as an 'accountingisation' of IC". Since accounting is based on the linear thinking (Bratianu and Vasilache, 2010) the evaluation of IC according to this metric cannot yield reasonable results.

In order to illustrate the paradox of measuring intellectual capital by using the accounting logic, let us consider the case of the Knowledge Balance Sheets (KBS) in Austrian public universities (Federal Law Gazette, 2006; Habersam et al., 2013, 2018). As a result of developing a reform of higher education in Austria, universities received in 2002 more autonomy by empowering the rectors with many decisions concerning the life of their universities. From simple executives of the decisions coming from the Ministry of Education, the rectors had to act now as top managers for their universities, like top managers in firms. "The Ministry deliberately forced public universities to become more like 'enterprises'”(Habersam et al., 2013, p. 324). The university autonomy has a twin dimension the accountability of the decision-makers. In this new university governance model, the Ministry decided to request mandatory a KBS from each state-funded university from 2007 onwards.

The Federal Law Gazette of the Republic of Austria, issued on 15 February 2006, Part II, published the $63^{\text {rd }}$ Regulation of the Federal Ministry of Education, Science and Culture on Intellectual Capital Reports (Intellectual capital Report Act - 
ICRA). The objectives of the ICR is presented in section 2 of this document: "The intellectual capital report aims at presenting, evaluating and communicating intangible assets, performance processes and their consequences and serves as a qualitative and quantitative basis for generating and entering a performance agreement". The part II of the content of ICR - Intellectual property is structured as follows: 1 . Human capital; 2 . Structural capital; and 3. Relational capital. It is clear that the composition of this part is using the canonical model of the intellectual capital discussed above. Then, the law indicates the indicators to be quantified within each of these basic components of the intellectual capital. For Human capital, the law considers the following indicators: staff per university, number of awarded teaching qualifications (habilitations), number of appointments to the university, number of appointments from the university, number of academic/art staff who have completed a temporary stay abroad amounting to at least 5 days (outgoing), number of incoming academic/art staff, and number of participants in programs for continuing education and personnel development.

In the section concerning Structural capital there are similar indicators, like: funding for measures promoting equal opportunities for men and women and affirmative action for women (euro), funding for measures advancing gender specific education and research/development and promotion of the arts (euro), number of staff active at special institutions, and so on. The final indicator is "floor space" in square meters. Regardless of the importance of these indicators considering the evaluation of the resources of a given university, these indicators have nothing to do with the idea of intellectual capital since they do not reflect intangible resources and they are based on linear thinking which is typical for accounting procedures. In such a situation we may ask how can somebody interpret data representing tangible resources as value for the intellectual capital of that university? The whole process of evaluation is flawed and there is no meaning of the final report. After many debates and reactions coming from some universities, the 53 performance indicators have been reduced to 26 , and then to 24 . However, the problem of using incorrectly tangible indicators for measuring intangible resources and applying the accounting logic remain. Thus, the reporting system introduced by this law is, in my view, meaningless with respect to the concept of intellectual capital.

\section{The golden rule for understanding the intellectual capital}

"It is 21 years since I began in the pioneering job as the world's first Director of Intellectual Capital at Skandia, where I developed the Skandia Navigator to support the strategic process of leveraging hidden assets... The Skandia Navigator model was the basis for the first official publication of a corporate IC annual report in the world in 1994. The origin of Skandia's IC Navigator was an attempt to visualise the hidden value, rather than account for, intangibles" (Edvinsson, 2013, p. 16). Reflecting on these ideas coming from one of the pioneers of intellectual capital research and practice, we may consider the following golden rule:

Keep the intellectual capital intellectual! 
That means to forget about all kind of proxies used for evaluating and reporting intellectual capital and to look to its intangible essence and its capacity to shape the future growth of the organization. We should be able to go beyond accounting and reporting the intellectual capital and understand its deep roots in the rational, emotional and spiritual knowledge.

\section{Conclusions}

Intellectual capital research and practice is at cross-roads and many people ask themselves about the future of this domain of study and management, especially due to the failing project of integrating it within the accounting framework. This accounting framework is built up on the linear logic and it cannot accommodate the complexity, intangibility, and nonlinearity of the intellectual capital. Thus, intellectual capital cannot be measured by using methods and techniques used for the tangible assets. The present paper is focused on the mythology created around the intellectual capital by all those researchers who could not understood these properties and the main questions raised by the pioneers of this domain of study. By using critical thinking and knowledge metaphors analysis the present paper identifies seven myths and reveals the hidden hypotheses which support them. Thus, we can understand the limitations introduced by these myths and possible errors in interpreting correctly any research concerning intellectual capital.

Myth \#1 is about the linearity property induced by the knowledge metaphor based on tangible objects. The paper demystifies this approach and states clearly that intellectual capital is nonlinear. Myth \#2 refers to the static feature of intellectual capital and its interpretation as a potential. In reality, intellectual capital is dynamic and is transforming continuously from a potential into an operational form. Myth \#3 discusses the rational attribute of the intellectual capital, attribute used by almost all the researchers and practitioners. However, as much as knowledge is not only rational, intellectual capital should have also emotional and spiritual dimensions. Myth \#4 refers to the canonical model of the intellectual capital which has been accepted by the majority of researchers, and which is composed of human capital, emotional capital and spiritual capital. Based on the discussion from the previous myth it is anticipated the fact that intellectual capital model should be developed to include the building blocks of rational, emotional and spiritual intangibles. Myth \#5 shows the obsession with the critical importance of the human capital in knowledge creation, sharing and usage. However, structural capital controls the human capital such that no matter how smart are the employees in a generic organization, their performance is limited by the framework of the structural capital. Myth \#6 identifies the error of creating a direct correlation between the potential of intellectual capital and the firm's performance. In reality, intellectual capital potential is transforming under the force of the nonlinear integrators into an operational capital which leads to the firm's performance. Finally, myth \#7 identifies the process of accountingisation of the intellectual capita, an error with severe consequences on the evaluation and reporting of the intellectual capital.

The paper closes with the golden rule of keeping intellectual capital intellectual. The only way of deepening the research into intellectual capital is to understand the intangible nature of the intellectual capital. The importance of present 
research for academics is in revealing the errors made in interpreting this complex entity in terms of Newtonian logic and accounting framework. The importance for practitioners results from showing that all the metrics based on the linearity property used in intellectual capital evaluation and reporting should be abandoned and replaced with new nonlinear metrics. The value of this paper results from the new lenses used in seeing and interpreting the complexity of intellectual capital.

\section{References}

Agoston, S. and Dima, A.M. (2012),"Modelling intellectual capital using Analytic Hierarchy Process (AHP)", in Surakka, J. (ed.). Proceedings of the $4^{\text {th }}$ European Conference on Intellectual Capital, 23-24 April 2012, Lisbon, Portugal, Academic Conference and Publishing International: Reading.

Albrecht, K. (2003), The power of minds at work: Organizational intelligence in action, American Management Association, New York.

Alvesson, M. and Spicer, A. (2016), The stupidity paradox: The power and pitfalls of functional stupidity at work, Profile Books, London.

Andriessen, D. (2004), Making sense of intellectual capital: Design a method for valuation of intangibles, Elsevier, Amsterdam.

Andriessen, D. (2006),“On the metaphorical nature of intellectual capital: A textual analysis”, Journal of Intellectual Capital, Vol. 7, No. 1, pp. 93-100.

Andriessen, D. (2008), "Stuff or love? How metaphors direct our efforts to manage knowledge in organizations", Knowledge Management Research \& Practice, Vol. 6, No. 1, pp. 5-12.

Andriessen, D. and Van den Boom, M. (2007),"East is East and West is West, and (n)ever its intellectual capital shall meet”, Journal of Intellectual Capital, Vol. 8, No. 4, pp. 641-652.

Barney, J.B. (1991), "Firm resources and sustained competitive advantage”, Journal of Management, Vol. 17, pp. 99-120.

Barney, J.B. and Hesterly, W.S. (2012), Strategic management and competitive advantage: Concepts and cases, International edition, Pearson, New York.

Basu, K. and Palazzo, G. (2008),“Corporate social responsibility: A process model of sensemaking”, Academy of Management Review, Vol. 33, No. 1, pp. 122-136.

Bejinaru, R. (2017), “Universities in the knowledge economy”, Management Dynamics in the Knowledge Economy, Vol. 5, No. 2, pp. 251-271.

Bismuth, A. and Tojo, Y. (2008), “Creating value from intellectual assets”, Journal of Intellectual Capital, Vol. 9, No. 2, pp. 228-245.

Bolisani, E. and Bratianu, C. (2017),"Knowledge strategy planning: An integrated approach to manage uncertainty, turbulence, and dynamics", Journal of Knowledge Management, Vol. 21, No. 2, pp. 233-253.

Bolisani, E. and Oltramari, A. (2012),"Knowledge as a measurable object in business contexts: A stock-and-flow approach”, Knowledge Management Research \& Practice, Vol. 10, No. 3, pp. 275-286.

Bontis, N. (1999),"Managing organizational knowledge by diagnosing intellectual capital: framing and advancing the state of the field", International Journal of Technology Management, Vol. 18, No. 5-8, pp. 433-462. 
Boroditsky, L. (2000),"Metaphoric structuring: Understanding time through spatial metaphors", Cognition, Vol. 75, pp. 1-28.

Branson, R. (2011), Screw business as usual, Virgin Books, London.

Bratianu, C. (2009),"The frontier of linearity in the intellectual capital metaphor", Electronic Journal of Knowledge Management, Vol. 7, No. 4, pp. 415-424.

Bratianu, C. (2010),"A critical analysis of Nonaka's model of knowledge dynamics", in Rodrigues, S. (ed.), Proceedings of the $2^{\text {nd }}$ European Conference on Intellectual Capital, ISCTE Lisbon University Institute, Lisbon, Portugal, 29-30 March 2010, pp. 115-120, Academic Conferences and Publishing International, Reading.

Bratianu, C. (2011),"A new perspective of the intellectual capital dynamics in organizations",in Vallejo-Alonso, B., Rodriguez-Castellanos, A. and ArreguiAyastuy, G. (eds.), Identifyi ng, measuring, and valuing knowledge-based intangible assets, pp. 1-21, IGI Global, Hershey.

Bratianu, C. (2013),"Nonlinear integrators of organizational intellectual capital", in Fathi, M. (ed.), Integration of practice-oriented knowledge technology: Trends and perspectives, pp. 3-17, Springer, Heidelberg.

Bratianu, C. and Andriessen, D. (2008),"Knowledge as energy: A metaphorical analysis", in Harorimana, D. and Watkins, D. (eds.), Proceedings of the $9^{\text {th }}$ European Conference on Knowledge Management, pp. 75-82, Academic Publishing Limited, Reading.

Bratianu, C. and Bejinaru, R. (2017),"Knowledge strategies for increasing IC of universities", in Lopez, I.T. and Serrasqueiro, R. (eds.), Proceedings of the $9^{\text {th }}$ European Conference on Intellectual Capital, Instituto Universitario de Lisboa (ISCTE), Portugal, 6-7 April 2017, pp. 34-42, Academic Conferences and Publishing International, Reading.

Bratianu, C. and Bolisani, E. (2015),"Knowledge strategy: An integrated approach for managing uncertainty", in Massaro, M. and Garlatti, A. (eds.), Proceedings of the $16^{\text {th }}$ European Conference on Knowledge Management, University of Udine, Italy, 3-4 September 2015, pp. 169-177, Academic Conferences and Publishing International, Reading.

Bratianu, C. and Orzea, I. (2013a),"The entropic intellectual capital model", Knowledge Management Research \& Practice, Vol. 11, No. 2, pp. 133-141.

Bratianu, C. and Orzea, I. (2013b),"Emotional knowledge: The hidden part of the iceberg", in Janiunaite, B., Pundziene, A. and Petraite, M. (eds.), Proceedings of the $14^{\text {th }}$ European Conference on Knowledge Management, Kaunas University of Technology, Lithuania, 5-6 September 2013, Vol.1, pp. 82-90, Academic Conferences and Publishing International, Reading.

Bratianu, C. and Orzea, I. (2013c),"Unfolding the Gordian Knot of the university intellectual capital", Electronic Journal of Knowledge Management, Vol. 11, No. 3, pp. 214-225.

Bratianu, C. and Vasilache, S. (2010),"A factorial analysis of the managerial linear thinking model", International Journal of Innovation and Learning, Vol. 8, No. 4, pp. 393-407.

Bratianu, C. and Vatamanescu, E.M. (2018),"The entropic knowledge dynamics as a driving force of the decision-making process", Electronic Journal of Knowledge Management, Vol. 16, No. 1, pp.1-12. 
Cuganesan, S. (2005)," Intellectual capital-in-action and value creation: A case study of knowledge transformation in an innovation process", Journal of Intellectual Capital, Vol. 6, No. 3, pp. 357-373.

Cuganesan, S. and Dumay, J. (2009),"Reflecting on the production of intellectual capital visualisations", Journal of Intellectual Capital, Vol. 14, No. 2, pp. 212226.

Damasio, A. (1999), The feelings of what happens: Body and emotions in the making of consciousness, Harcourt, New York.

Damasio, A. (2012), Self comes to mind: Constructing the conscious brain, Vintage Books, New York.

Descartes, R. (1997), Key philosophical writings, Wordsworth Editions, Hertfordshire.

Devinney, T.M. (2009),"Is the socially responsible corporation a myth? The good, the bad, and the ugly of corporate social responsibility", The Academy of Management Perspectives, Vol. 23, No. 2, pp. 44-56.

Dima, A.M. and Ghinea, V. (2016),"A model of academic leadership", in Pinzaru, F. and Bratianu, C. (eds.), Proceedings of the $12^{\text {th }}$ European Conference on Management, Leadership, and Governance, 10-11 November 2016, SNSPA, Bucharest, Romania, Academic Conferences and Publishing International, Reading.

Dumay, J. (2012),"Grand theories as barriers to using IC concepts", Journal of Intellectual Capital", Vol. 13, No. 1, pp. 4-15.

Dumay, J. (2016),"A critical reflection on the future of intellectual capital: from reporting to disclosure", Journal of Intellectual Capital, Vol. 17, No. 1, pp. 168184.

Edvinsson, L. (2013),"IC 21: Reflections from 21 years of IC practice and theory", Journal of Intellectual Capital, Vo. 14, 1, pp. 163-172.

Edvinsson, L. and Malone, M. (1997), Intellectual capital: Realising your company's true value by finding its hidden brainpower, Harper Collins, New York.

Ekman, P.E. (2003), Emotions revealed: Recognizing faces and feelings to improve communication and emotional life, Times Books, New York.

Gartner, H. (1983), Frames of mind: The theory of multiple intelligences, Basic Books, New York.

Gentner, D., Bowdle, B., Wolff, Ph. and Boronat, C. (2001), Metaphor is like analogy, in Gentner, D., Holyoak, K.J. and Kokinov, B.N. (eds.), The analogical mind: Perspectives from cognitive Science, pp. 199-254, The MIT Press, Cambridge.

Ghinea, V.M. and Bratianu, C. (2012),"Organizational culture modelling”, Management \& Marketing, Vol. 7, No. 2, pp. 257-276.

Giuliani, M. (2015),"Rome wasn't built in a day ... reflecting on time, intellectual capital and intellectual liabilities", Journal of Intellectual Capital, Vol. 16, No. 1, pp. 219.

Gladwell, M. (2005), Blink: The power of thinking without thinking, Back Bay Books, New York.

Goran, R., Pike, S. and Fernstörm, L. (2005), Managing intellectual capital in practice, Elsevier, Amsterdam.

Goran, R. and Jutur, S. (2005), Intellectual capital management: A strategic perspective, The ICFAI University Press, Hyderabad. 
Grant, R. (1996),"Prospering in dynamically-competitive environments: organizational capability as knowledge integration", Organization Science, Vol. 7, No. 4, pp. 375-387.

Habersam, M., Piber, M. and Skoog, M. (2013),"Knowledge balance sheets in Austrian universities: The implementation, use, and re-shaping of measurement and management practices", Critical Perspectives on Accounting, Vol. 24, pp. 319337.

Habersam, M., Piber, M. and Skoog, M. (2018),"Ten years of using knowledge balance sheets in Austrian public universities: A retrospective and prospective view", Journal of Intellectual Capital, Vol. 19, No. 1, pp. 34-52.

Hadad, S. (2017),"Strategies for developing knowledge economy in Romania", Management \& Marketing. Challenges for the Knowledge Economy, Vol. 12, No. 3, pp. 416-430.

Hill, D. (2008), Emotionomics: Leveraging emotions for business, Revised edition, Kogan Page, London.

Kianto, A. (2007),"What do we really mean by the dynamic dimension of intellectual capital?", International Journal of Learning and Intellectual Capital, Vol. 4, No. 4, pp. 342-356.

Kianto, A., Inkinen, H., Ritala, P. and Vanhala, M. (2017),"A temporal perspective to intellectual capital dynamics: How has IC changed in Finnish firms from 2013 to 2017?", in Tsui, E. and Cheung, B. (eds.), Proceedings of the 14th International Conference on Intellectual Capital, Knowledge Management \& Organizational Learning, pp. 134-138, The Hong Kong Polytechnic University, Hong Kong, 7-8 December 2017, Academic Conferences and Publishing International, Reading.

Lakoff, G. and Johnson, M. (1980), Metaphors we live by, Chicago University Press, Chicago.

Lakoff, G. and Johnson, M. (1999), Philosophy in the flesh: The embodied mind and its challenge to western thought. Basic Books, New York.

Marr, B. (Ed.)(2005), Perspectives on intellectual capital, Elsevier Butterworth Heinemann, Boston.

MERITUM (2002), Guidelines for managing and reporting of intangibles, Fundacion Airtel Movil, Madrid.

Mouritsen, J. and Larsen, H.T. (2005),"The $2^{\text {nd }}$ wave of knowledge management: The management control of knowledge resources through intellectual capital information", Management Accounting Research, Vol. 16, pp. 371-394.

Nissen, M.E. (2006), Harnessing knowledge dynamics: Principled organizational knowing \& learning, IRM Press, London.

Nonaka, I. and Takeuchi, H. (1995), The knowledge-creating company: How Japanese companies create the dynamics of innovation, Oxford University Press, New York.

Pinker, S. (2008), The stuff of thought: Language as a window into human nature, Penguin Books, New York.

Porter, M.E. and Kramer, M.R. (2011),"Creating shared values: How to reinvent capitalism - and unleash a wave of innovation and growth", Harvard Business Review, January-February 2011, pp. 63-77. 
Ricceri, F. (2008), Intellectual capital and knowledge management: Strategic management of knowledge resources, Routledge, London.

Roos, G., Pike, S. and Fernström, L. (2005), Managing intellectual capital in practice, Elsevier, Amsterdam.

Russell, B. (1972), A history of Western philosophy. Simon and Schuster, New York.

Schein, E.H. (2004), Organizational culture and leadership, $3^{\text {rd }}$ edition, Jossey-Bass, San Francisco.

Spender, J.C. (2015),"'The theory of management firm (TMF)", Human Systems Management, Vol. 34, No. 1, pp. 57-80.

Stewart, T.A. (1997), Intellectual capital: The new wealth of organizations, Doubleday/Currency, New York.

Stewart, T. A. (1999), Intellectual capital: The new wealth of organizations, Nicholas Brealey Publishing, London.

Sveiby, K.E. (1997), The new organizational wealth: Managing and measuring knowledge based assets, Berret Koehler, San Francisco.

Teece, D., Pisano, G. and Shuen, A. (1997),"Dynamic capabilities and strategic management", Strategic Management Journal, Vol. 18, pp. 509-533.

Wernerfelt, B. (1984),"A resource-based view of the firm", Strategic Management Journal, Vol. 5, pp. 171-180.

Zack, M. (2005),"The strategic advantage of knowledge and learning", International Journal of Learning and Intellectual Capital, Vol. 2, No. 1, pp. 1-20.

Zohar, D. and Marshall, I. (2000), Spiritual intelligence: The ultimate intelligence, Bloomsbury, London.

Zohar, D. and Marshall, I. (2004), Spiritual capital: Wealth we can live by, BerrettKoehler Publishers, San Francisco.

*** The Free Online Dictionary of Computing, http://www.dictionary.die.net (retrieved 18 May 2018).

*** Federal Law Gazette of the Republic of Austria, issued on 15 February 2006, Part II, $63^{\text {rd }}$ Regulation of the Federal Ministry of Education, Science and Culture on Intellectual Reports (Intellectual Capital Report Act - ICRA). 